\title{
ANALISA PENENTUAN WATER VAPOR TERHADAP PENGARUH ERUPSI GUNUNG SINABUNG MENGGUNAKAN DATA SUGAR DAN CITRA SATELIT TERRA MODIS
}

\author{
Safridatul Audah ${ }^{1,}$ Mokhammad Nur Cahyadi ${ }^{2,}$ Muhammad Taufik $^{2}$ \\ ${ }^{1 .}$ Politeknik Aceh Selatan \\ 2. Jurusan Teknik Geomatika, FTSP, Institut Teknologi Sepuluh Nopember \\ ${ }^{1 .}$ Komplek Reklamasi Pantai. JL. Mardeka, Tapak Tuan, Kabupaten Aceh Selatan, Indonesia \\ 2.Jl. Arief Rahman Hakim, Kampus Keputih, Sukolilo Surabaya, Kode Pos 60111, Indonesia \\ E-mail: Safridatul@yahoo.co.id
}

\begin{abstract}
The eruption of Mount Sinabung in 2010 caused bursts of volcanic ash particles into the atmosphere layer to impact the weather. This is because volcanic ash is hydrocopic which can cause condensation process and block the process of solar radiation earth surface. Precivitable Water vapor (PWV) as one of the parameters of the atmosphere that can be used as information to determine the weather conditions in an area. Utilization of data Sumatran GPS Array (SUGAR) and data satellite Terra sensors MODIS (Moderate Resolution Imaging Spektroradiometer) can be used to find out PWV through GPS inversion method by utilizing estimated estimation of slowing and rotating GPS signals overlaid with troposphere. While the transmittance method is performed by comparing the surface reflectance between the channel absorption and the channel non absorption contained in the sensor MODIS. The results showed that spatial variation of PWV distribution pattern showed wetness pattern during eruption. This was indicated by some areas that have PWV distribution pattern almost in each region and PWV verification result from GPS showed $\pm 47.65 \mathrm{~mm}-66.81 \mathrm{~mm}$, while PWV value from MODIS ranges from $\pm 13.02 \mathrm{~mm}-80.05 \mathrm{~mm}$. Based on the results of PWV-GPS correlation test from June to October of 2010 has a correlation coefficient of 0.0173 to PWV from MODIS and explains the positive relationship between PWV of GPS with PWV value from MODIS, but correlation value of the variable variables including low category because of location points Station SUGAR are spread unevenly and are more likely to spread along the western coast of Sumatra, which borders the Indian Ocean.
\end{abstract}

Keywords: Mount Sinabung, Precipitable Water Vapor, SUGAR, MODIS.

\section{Pendahuluan}

Atmosfer adalah suatu lapisan udara yang mengelilingi bumi. 75\% dari massa atmosfer yang terdapat awan, hujan dan konversi udara. Lapisan ini mempunyai pengaruh yang besar terhadap kehidupan semesta, seperti meredam panas matahari, merambatkan gelombang - gelombang suara, menimbulkan gejala senja, dan memegang peranan yang sangat penting dalam perubahan cuaca [16].

Gejala fisis atmosfer yang terjadi akibat letusan gunung merapi yang mengeluarkan awan panas dalam bentuk abu vulkanik yang menyembur ke lapisan atmosfer bumi dapat menyebabkan dampak yang cukup signifikan. Partikel debu vulkanik yang dikeluarkan dalam lapisan troposfer bumi akan menghalangi proses radiasi matahari dan tidak dapat masuk kepermukaan bumi sehingga menyebabkan suhu di daerah tersebut rendah (menurun), lebih dari itu partikel debu vulkanik tersebut bersifat higroskopis, yakni dapat mengikat uap air, sehingga dapat memicu proses terjadinya kondensasi dan terbentuklah awan dengan (kelembaban) tinggi. Hal ini tente saja akan mempengaruhi pola sistem cuaca, karena radiasi matahari merupakan salah satu unsur utama dari unsur-unsur yang mempengaruhi cuaca.

Pada peristiwa letusan gunung berapi ratusan ton sulfur yang menyembur ke atmosfer dengan kecepatan vertical tertentu sehingga dapat menembus ke lapisan tropofer dan lapisan stratosfer yang akan terditribusi ke tempat yang lebih luas dan jauh mengikuti sirkulasi global. Kemudian sulfur akan bereaksi dengan oksigen dan uap air membentuk aerosol sulfat yang mampu menahan pancaran sinar matahari yang memasuki atmosfer bumi (transmitansi) sehingga berpotensi menyebabkan pendinginan global, karena uap air merupakan salah satu komponen yang berada di atmosfer bumi dalam 
jumlah kecil yang dapat mempengaruhi aktivitas kehidupan di bumi [5].

Uap Air adalah campuran antara zat oksigen dan hydrogen yang mengalami reaksi kimia dan dengan bantuan panas matahari berubah bentuk menjadi zat cair, terletak di atmosfer pada ketinggian 8000 $9000 \mathrm{Km}$. Uap air pada daerah tropis akan mengisi 4 $\%$ dari total volume udara, sedangkan pada daerah sedang hanya mengisi kurang dari $1 \%$ dari total volume udara. Uap air memiliki kemampuan untuk menyerap energi, sehingga tidak semua energi lolos melewatinya. Uap air memegang peranan penting dalam proses penentuan cuaca, merupakan penyerap radiasi sehingga mempengaruhi keseimbangan energi di atmosfir dan berperan dalam pelepasan panas dari proses kondensasi sehingga memelihara prosesproses yang terjadi di atmosfir [9].

Pemantauan ruang berbasis seperti Global Positioning System (GPS) dan penginderaan jauh dari satelit adalah satu-satunya cara yang efektif untuk menilai tingkat uap air secara global dan berbagai misi telah dilaksanakan untuk pengukuran precipitable water vapor $(P W V)$ atau total kandungan uap air [3,10-11].

Teknik pengamatan GPS telah dilakukan untuk mengukur variabilitas atmosfer (temperatur, tekanan, dan kelembapan) dengan menentukan beda fasa atau sudut pembelokan sinyal dari satelit GPS yang diterima oleh satelit orbital rendah melalui pendekatan indeks refraktifitas medium perambatan. [2]

Selain GPS, aplikasi lain yang digunakan seperti penginderaan jauh dapat digunakan untuk menurunkan informasi transmitan uap air dengan melakukan perbandingan reflektan permukaan antara kanal absorbsi dan kanal non absorbsi dengan mengabaikan pengaruh variasi reflektansi permukaan [8].

Isu perubahan iklim telah memicu pengembangan model prediksi curah hujan, mengingat variabilitas curah hujan merupakan kontrol dinamika atmosfer. Curah hujan dapat diestimasi dari PWV atau total kandungan uap air dalam kolom atmosfer. Dari uraian di atas, maka perlu dilakukan penelitian untuk menganalisis tentang PWV di atmosfer khususnya pada lapisan troposfer, sehingga diketahui kadar uap air di daerah terjadinya letusan Gunung Sinabung yang diperoleh melalui instumen citra satelit Terra MODIS dan GPS. Kedua aplikasi ini dapat dijadikan acuan untuk pengembangan sistem prediksi prakiraan cuaca dan lain-lainnya.

\section{Metode Penelitian}

Data yang digunakan adalah data Sumatran GPS Array (SUGAR) yang merupakan bagian dari proyek
SOPAC dan hasil kerjasama antara Earth Observing System (EOS) Singapura dan Lembaga Ilmu Pengetahuan Indonesia (LIPI). Lokasi Penelitian dapat dilihat pada Gambar 1. Selanjutnya digunakan juga data citra satelit Terra MODIS LIB yang mencakup sebagian wilayah Kecamatan Sumatera Utara, khususnya bagian yang terkena dampak dari letusan Gunung Sinabung pada bulan Agustus 2010.

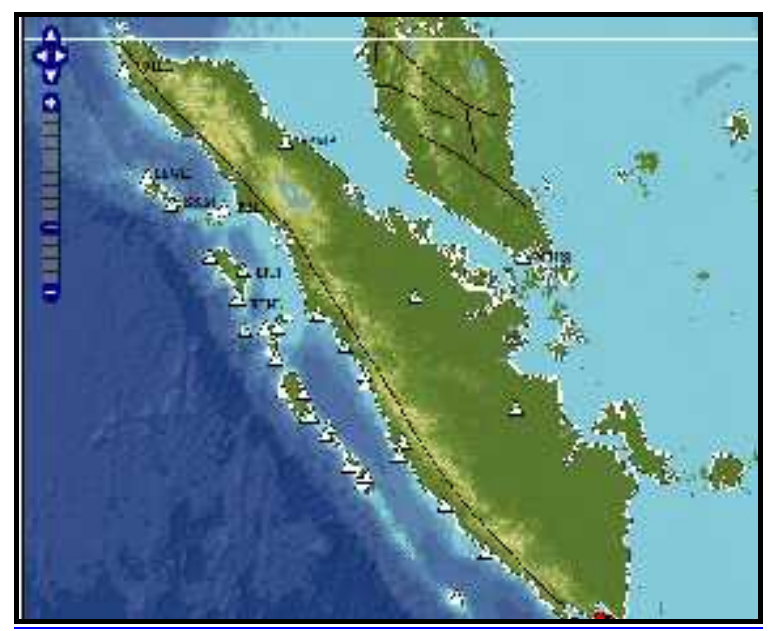

Gambar.1. Letak posisi stasiun GPS-SUGAR

Sumber : http://sopac.ucsd.edu/map.shtml )

a) Pengolahan data GPS

Secara umum, proses pengolahan data GPS ini dapat dibagi menjadi beberapa tahap, yaitu: Pengestimasian nilai ZTD dengan cara membuat direktori kerja seperti rinex, brdc untuk data broadcast ephemeris, igs untuk data final ephemeris didalam direktorik kerja dan direktori tables. Proses pengolahan GAMIT akan menghasilkan beberapa bentuk o-file, z-file Setelah itu, dilakukan ekstraksi fungsi metutil di GAMIT dengan aturan: stasiun yang memiliki sensor meteorology menggunakan input data o-file dan m-file (RINEX dari sensor meteorologi permukaan). Sedangkan stasiun yang tidak ada sensor meteorology menggunakan input data o-file dan z-file (model dari troposheric delay dari GPT50). Data yang dihasilkan dari ekstraksi sh_metutil tersebut itu berupa nilai tabular dari ZTD, ZHD dan PWV.

\section{b) Pengolahan data Citra Terra MODIS}

Metode penginderaan jauh melalui penurunan transmitan pada pendeteksian absorbsi radiasi matahari uap air dari kanal-kanal yang terdapat pada Citra Terra MODIS.

MODIS (Moderate Resolution Imaging Spectrora diometer) adalah salah satu instrument pengamatan 
untuk menganalisa lahan, lautan, atmosfir bumi dan interaksi di dalamnya [4].

Dalam menurunkan transmitan uap air pada prinsipnya didasarkan oleh uap air [13]. Radiasi matahari yang dimaksud adalah radiasi matahari yang direflektansikan setelah ditransmisikan ke permukaan bumi dan dipantulkan kembali ke atmosfer. Menurut Kaufman and Gao [1] Teknik perbandingan 3 kanal dapat digunakan untuk menurunkan jumlah kandungan uap air di atmosfer pada derah permukaan daratan yang bebas awan, sedangkan teknik perbandingan 2 kanal digunakan pada wilayah sun glint di laut serta di awan. kanal yang digunakan pada citra satelit Terra MODIS untuk menurunkan transmitan uap air antara lain kanal 2 dan kanal 5 sebagai kanal non-absorbs dengan nilai panjang gelombang masing-masing yaitu $0.865 \mu \mathrm{m}$ dan 1.240 $\mu \mathrm{m}$. Kanal 17, 18 dan 19 digunakan sebagai kanal absorbsi dengan nilai panjang gelombang masingmasing kanal sebesar $0.905 \mu \mathrm{m} .0 .936 \mu \mathrm{m}$ dan 0.940 $\mu \mathrm{m}$.

\section{Hasil dan Pembahasan}

\subsection{Hasil Pola Distribusi PWV secara Spasial}

Analisa PWV secara variasi spasial yang diperoleh dari pengolahan data GPS dan data MODIS ini dilakukan dengan melihat pola distribusi PWV untuk diketahui informasi cuaca atmosfer di Sumatera Utara khususnya daerah yang terkena dampak letusan Gunung Sinabung.

Proses penggambaran variasi spasial pada penelitian ini menggunakan interpolasi kriging yang terdapat pada software ArcGis 10.3. Kriging adalah metode geostatistik yang digunakan untuk mengestimasi nilai dari sebuah titik yang terdapat disekitar titik yang akan diketahui nilainya dan tidak memperhatikan tren atau perubahan pada nilai variansi. Berikut ini merupakan penggambaran variasi spasial distribusi PWV harian dari pengolahan data GPS dan data MODIS

Hasil penggambaran variasi spasial berupa peta pola sebaran PWV yang disajikan dalam bentuk peta gradasi warna yang mengidentifikasikan besaran pola water vapor yang terjadi. Semakin cerah warnanya maka akan semakin tinggi nilai informasi water vapor yang diberikan.

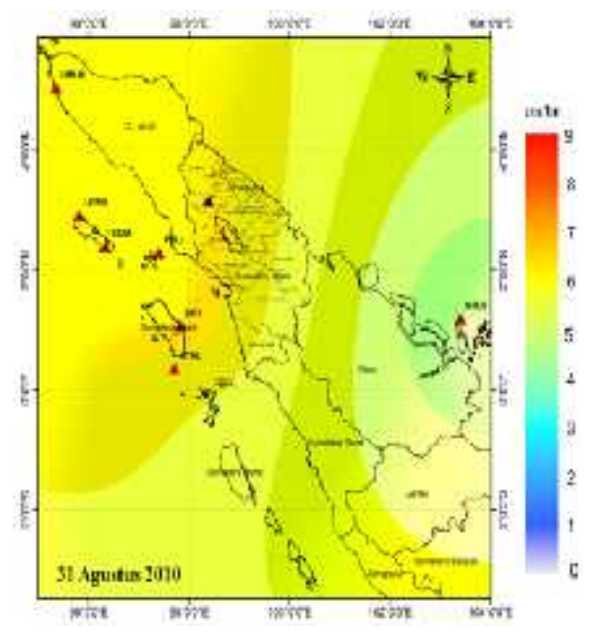

Gambar.3. Peta pola sebara PWV dari GPS

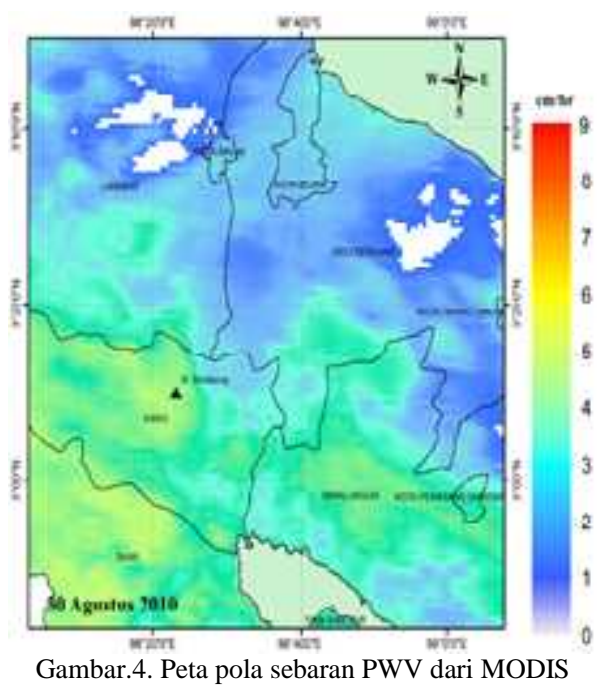

Pola distribusi PWV pada Gambar 3 dan Gambar 4 menampilkan pola persebaran PWV yang memiliki nilai yang berbeda-beda. dan relative tinggi selain itu kondisi iklim yang digambarkan memperlihatkan pola kebasahan pada saat tejadinya erupsi, hal ini ditandai dengan beberapa wilayah yang miliki pola sebaran PWV hampir disetiap daerah. cukup tinggi dengan nilai gradasi warna lebih tinggi. Hal ini dikarena perbedaan kondisi topografi di setiap daerah Sumatera Utara terletak di kawasan rawan bencana seperti letusan gunung api, [6] jika dikaitkan dengan lintang dan bujurnya, provinsi Sumatera Utara dibatasi oleh Selat Malaka di sebelah timur dan Samudera Hindia di sebelah barat, Posisi geografis ini mengakibatkan gangguan cuaca ekstrim regional yang terjadi di perairan tersebut berdampak signifikan terhadap kondisi cuaca lokal di Sumatera Utara. Selain itu, Sumatera sebagai pulau besar di Indonesia bagian barat, berpotensi mengalami pola gangguan musiman (monsoon) dan lokal. Sehingga 
dapat disimpulkan bahwa keadaan topografi memperngaruhi pola distribusi PWV. Hasil analisis ini sesuai dengan teori [7-12].

\subsection{Validasi Data PWV GPS dan PWV Citra Terra MODIS}

Valisasi data dilakukan untuk melihat kekuatan hubungan PWV hasil pengamatan GPS dengan PWV hasil teknik pengukuran MODIS. Maka, kedua data ini akan dicari hubungan keduanya yaitu hasil PWV dari pengolahan GPS dan hasil PWV dari pengolahan MODIS.

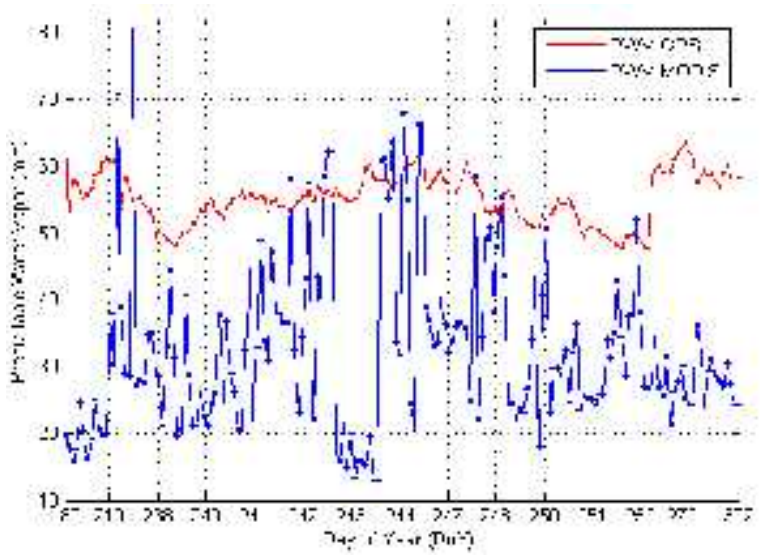

Gambar 5. Grafik perbandingan PWV- MODIS dan PWV- GPS

Gambar 3. dapat dilihat hasil ploting antara PWV hasil MODIS dengan PWV hasil pengamatan GPS. Hasil verifikasi PWV di Gunung Sinabung pada periode Juni - Oktober 2010 menunjukkan bahwa PWV yang diestimasi dari data MODIS berkisar 13,20 mm - 80,05 mm; nilai reratanya adalah $32,41 \mathrm{~mm}$. Sedangkan PWV dari pengolahan GPS berkisar 47,65 $\mathrm{mm}$ - 66,81 $\mathrm{mm}$; nilai reratanya adalah 55,31 mm. Maka dari nilai-nilai tersebut dapat disimpulkan bahwa PWV dari pengolahan data pengamatan GPS yang dihasilkan dari penelitian ini masih memiliki kesesuaian yang tinggi dengan nilai PWV dari MODIS. Selisih antara PWV dari GPS dengan nilai PWV dari MODIS masih relatif besar, dikarenakan adanya perbedaan dan koreksi tinggi terhadap pengukuran PWV yang dilakukan oleh MODIS terhadap pengukuran PWV oleh GPS

Pada uji korelasi dilakukan perhitungan korelasi dengan membandingkan PWV hasil GPS dengan PWV hasil MODIS. Hal ini digunakan untuk melihat sejauh mana kedekatan atau ketelitian dari kedua data tersebut yang divisualisasikan pada grafik.

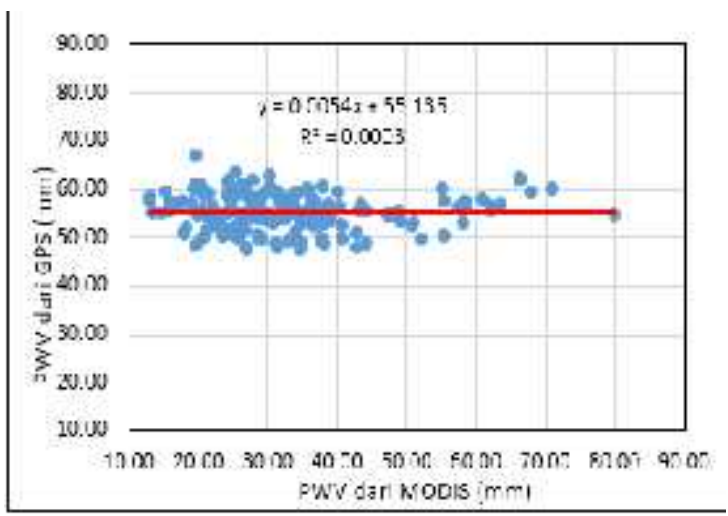

Gambar 6. Scatter plot nilai PWV-MODIS dan PWV-GPS

Dari scatter plot (Gambar 6.) didapatkan nilai koefisien korelasi 0.0173 . Hal ini berati adanya hubungan positif antara PWV MODIS dengan PWV GPS, namun nilai korelasi hubungan variabel tersebut termasuk katagori rendah [14]. Dengan demikian, dapat disimpulkan bahwa PWV MODIS memiliki hubungan rendah terhadap PWV dari GPS, hal ini bisa terjadi karena lokasi titik Stasiun SUGAR yang tersebar tidak merata dan lebih cenderung tersebar di sepanjang pantai barat Sumatera yang berbatasan dengan Samudera Hindia. Sedangkan untuk analisa PWV sesuai dengan nilai koefisien determinasi sebesar 0,0003. Hal ini menunjukkan kemampuan variabel PWV dalam memperngaruhi rata-rata nilai PWV sebesar $0.03 \%$ sedangkan sisanya sebesar 99,97\% dipengaruhi oleh factor lain. Dan untuk persamaan regresi linier diperoleh $0,0054 \mathrm{x}+$ 55,135. Nilai konstanta dari persamaan tersebut sebesar 0,0054, menunjukkan besarnya variabel PWV rata-rata GPS dan PWV MODIS memiliki hubungan yang lemah karena hubungan keduanya mendekati 0. Sedangkan koefisien regresi sebesar 55,135 diartikan memiliki hubungan positif.

\section{Kesimpulan}

Teknik penginderaan jauh seperti GPS dan Citra satelit Terra MODIS dapat digunakan sebagai alat yang mampu memberikan informasi dalam menentukan pola sebaran kandungan uap air (PWV). maka adapun kesimpulan yang dapat diberikan dari hasil penelitian tersebut adalah:

a) Hasil penggambaran pola distribusi secara spasial memperlihatkan pola kebasahan pada saat tejadinya erupsi, hal ini ditandai dengan beberapa wilayah yang miliki pola sebaran PWV hampir disetiap daerah. cukup tinggi dengan nilai gradasi warna lebih tinggi. Hal ini dikarena perbedaan kondisi topografi di setiap daerah Sumatera Utara terletak di kawasan rawan bencana seperti letusan 
gunung api yang dikaitkan pada bencana meteorologis mengakibat gangguan cuaca ekstrim.

b) Secara umum hasil verifikasi PWV GPS di Gunung Sinabung pada tahun 2010 berkisar antara $\pm 47,65 \mathrm{~mm}-66.81 \mathrm{~mm}$, sedangkan nilai PWV dari Satelit MODIS berkisar $\pm 13.02 \mathrm{~mm}$ $80,05 \mathrm{~mm}$.

c) Berdasarkan hasil uji korelasi PWV-GPS periode Juni - Oktober tahun 2010 mempunyai koefisien korelasi sebesar 0,0173 terhadap PWV-MODIS dan menjelaskan adanya hubungan positif antara PWV-GPS dengan PWV-MODIS, namun nilai korelasi hubungan variabel tersebut termasuk katagori rendah hal ini bisa terjadi karena lokasi titik Stasiun GPS SUGAR yang tersebar tidak merata dan lebih cenderung tersebar di sepanjang pantai barat Sumatera yang berbatasan dengan Samudera Hindia.

\section{Daftar Pustaka}

[1] Audah, S., 2016, "Pemanfaatan Data Citra Satelit Terra Modis Untuk Monitoring Precipitable Water Vapor Di Gunung Sinabung Sumatera Utara", Proseding SNTR III., Politeknik Aceh Selatan. hal. $105-110$

[2] Aoyama, Y., Shoji, Y., Mousa, A., Tsuda, T., Nakamura, H. 2004, "Temperature and Water Vapor Profiles Derived from Downward-Looking GPS Occultation Data", J. Meteor. Soc. Japan. Vol. 82 , hal.433-440.

[3] Chaboureau, J.P., A. Chédin, and N. A. Scott, 1998, "Remote sensing of the vertical distribution of the atmospheric water vapor from the TOVS observations: methodand validation", Journal of Geophysical Research, Vol.103, No.(D8), hal.8743- 8752.

[4] Danoedoro, Projo, 2012. Pengantar Penginderaan Jauh Digital. CV andi offset. Yogyakarta.

[5] Hamdi, S., 2014, "Kajian Peningkatan Kandungan Aerosol Stratosfer Akibar Letusan Gunung Berapi". Penelitian Pusat Sains dan Teknologi Atmosfer, Berita Dirgantara LAPAN, Vol.15, No.2, Hal 4049.

[6] Handayani, A.S., 2010,“Analisis Daerah Endemik Bencana Akibat Cuaca Ekstrim di Sumatera Utara “, Jurnal Meteorologi dan Geofisika Vol. 11. No. 1. hal. 54 - 58. Handoko, (1995), Klimatologi Dasar, Pustaka Jaya.

[7] Hidayat., T, 2011, "Tinjauan Kandungan Uap Air di Atmosfer untuk Penentuan Situs Astronomi di Indonesia", Prosidings Seminar Himpunan Astronomi Indonesia, Eds: Dermawan et al., Institud Teknologi Bandung, hal. 57-60.
[8] Kaufman, Y.J, and B.C. Gao, 1992. Remote sensing of water vapor in the near IR from EOS/MODIS. IEEE Trans. Geosci. Remote Sens. Vol. 30, No.5: $871-884$.

[9] Miller, A., Thompson, J. C., Peterson, R. E. and Haragan, D. R., 1983, "Elements of Meteorology", Charles E. Merrill Publishing Company, Fourth edition, Columbus.

[10] Mockler,S. B., 1995, Water Vapor In The Climate System., American Geophysical Unio, Jeky 11 Island, Georgia. http://www.agu.org/sci_soc/mockler.html

[11] Randel, D.L., T.J. Greenwald, T.H. Vonder Haar, G.L. Stephens, M.A. Ringerud, and C.L. Combs. ,1996, "A new global water vapor dataset", Bulletin of the American Meteorological Society, Vol.7, No.6, hal.1233-1254.

[12] Setiawan, P. dkk., 2006, "Estimasi Air Mampu Curah Menggunakan Data MODIS sebagai Informasi Cuaca Spasial di Pulau Jawa" Jurnal Penginderaan Jauh, Vol. 3, No.1, hal.64-76.

[13] Sopan Parwati, dkk., 2005, Verifikasi Air Mampu Curah dari Data MODIS Untuk Mendukung Informasi Cuaca Spasial dilahan Pertanian Pulau Jawa. Jurnal Pemanfaatan Efektif Penginderaan Jauh Untuk Peningkatan Kesejahteraan Bangsa. MAPIN XIV. hal.85-93.

[14] Sugiyono., 2007, Hipotesis Statistik. Universitas Pendidikan Indonesia.

[15] Susilo., 2012, Precipitable Water Vapor (PWV) di Wilayah Jawa Barat menggunakan GPS Kontinu. Thesis, Institut Teknologi Bandung.

[16] Trewartha, G. T dan L. H., Horn., 1980, “An Introduction to climate, $5^{\text {th }}$ ed., Mc-Grawl_Httl". International Company. New York. 